\title{
Transfusion Transmitted Diseases Among Blood Donors in Tertiary Care Teaching Hospital of Central India
}

\author{
Ashok Yadav and Ravi Jain* \\ Dept. of Pathology, MGM Medical College, Indore, India
}

ABSTRACT

Introduction: Transmission of infectious diseases through donated blood is of concern to blood safety as transfusion forms an integral part of medical and surgical therapy. Among all infections HIV and hepatitis are the most dreadful.

Aims \& Objectives: To find out the Seroprevalence of transfusion-transmissible infections in blood donors, to find the incidence of spectrum of diseases in blood bank donation, to find the age distribution of the cases studied.

Material \& Methods: The present study is being undertaken in the Department of Pathology MGM Medical College Indore. This is a retrospective study that was conducted, during the period $2001-2016$. Tests are routinely done on every blood unit to exclude HIV, HBV, HCV, syphilis and malaria. The screening for HIV was done by ELISA using kits. HBS Ag was detected by ELISA. Anti-HCV test was done by ELISA\& Syphilis by VDRL.

Results; In the present study, 241571 blood donors were observed in the year 2001-16, majority of donors are voluntary donors $68.13 \%$ as compared to replacement/relative donors $31.86 \%$. Majority of donors are male donors $96.25 \%$ as compared to female donors $3.74 \%$. Seroprevalence of HBV,HCV, HIV \& SYPHILIS are $1.80 \%, 0.098 \%, 0.20 \%$ and $0.26 \%$ respectively. Seroprevalence is higher in the age group 26-35 years. Overall seropositivity of TTI's (HIV,HBV, HCV, Syphilis \& Malaria) is higher in replacement donors $3.12 \%$ as compared to voluntary donors $2.01 \%$. Over all Seroprevalence of transfusion transmitted disease in all donations in the year 2001-16 is 2.36 \%. Conclusion -Voluntary blood donation should be encouraged for prevention of transfusion-transmissible diseases.

Keywords: Hepatitis B, Hepatitis C, Transfusion Transmitted Diseases, Voluntary Donors, Syphilis, Replacement Donors

\section{Introduction}

Transmission of infectious diseases through donated blood is of concern to blood safety as transfusion forms an integral part of medical and surgical therapy. Blood transfusion carries the risk of transfusion-transmissible infections, including HIV, hepatitis, syphilis, malaria and infrequently toxoplasmosis, Brucellosis and some viral infections like CMV, EBV and herpes.

With every unit of blood, there is $1 \%$ chance of transfusionassociated problems including transfusion-transmitted diseases.Among all infections HIV and hepatitis are the most dreadful. By this study, we intend to find out the seroprevalence of Transfusion transmitted diseases amongst blood donors \& age distribution of Transfusion transmitted diseases amongst blood donors.

Infectious Agents ${ }^{1}$ There are four main groups of microorganisms known to cause infections namely viruses, bacteria, protozoa and fungi. Only first three groups of microbes - viruses, bacteria and protozoa - have been reported to be transmitted by blood transfusion.

Viruses Viruses are the simplest forms of life. Following are some of the viruses which are known to be transmitted through blood ${ }^{2,3}$ :
1. Human immunodeficiency virus (HIV)

2. Hepatitis B virus

3. Hepatitis $\mathrm{C}$ virus

4. Hepatitis A virus

5. Hepatitis $\mathrm{G}$ virus

6. Non - A, Non - B Hepatitis

7. Epstein Barr Virus

8. Cytomegalo virus (CMV)

9. Human T Lymphocytic virus (HTLV - $1 \&$ HTLV - 2)

SyphilisSyphilis, an ancient diseaseis caused by Spirochete Treponema pallidum. According toThe World Health organization estimates ${ }^{4}$, there are approximate 12 million new cases diagnosed each year. Syphilis has acquired new potential for morbidity with the advent of HIV \& AIDS.

Syphilis is a chronic disease caused by Treponema pallidum. Treponemes (trepos - to turn \& nema - thread )$^{6}$ are relatively short, slender spirochetes with fine spirals $\&$ pointed or round ends. Transfusion transmitted Syphilis - The first case of Transfusion transmitted syphilis was reported in $1915^{5} .138$ cases were reported in the literature by $1941^{7}$. Cases were mostly discovered in donors with 
primary or secondary stage of disease ${ }^{8}$. Treponemes are senisitve to cold; hence risk of transmission through stored blood at $4-8^{\circ} \mathrm{C}$ is very low ${ }^{9-10}$.

In India, most blood donors are first-time donors ${ }^{5}$. The prevalence of syphilis among blood donors in India was reported to be $0.7 \%{ }^{11}$. The global incidence of syphilis in blood donors is variable ranging from $0.75 \%$ in Pakistan ${ }^{12}$ to $12.7 \%$ in Tanzania ${ }^{13}$.

Aims and Objectives: The study was conducted in the department of pathology, M.G.M.M.C, Indore.

1. To find out the seroprevalence of Transfusion transmitted diseases (HBV , HCV ,HIV \& syphilis) in blood donors.

2. To find the incidence of spectrum of diseases in blood bank donation.

3. To find the age distribution of the cases studied.

\section{Material and Methods}

The present study is being undertaken in the Department of Pathology MGM Medical College Indore. This is a retrospective study that was conducted, during the period $2001-2016$. Tests are routinely done on every blood unit to exclude HIV, HBV, HCV, syphilis and malaria. Donors were selected by the standard criteria for donor fitness. The screening for HIV was done by ELISA using kits. HBS Ag was detected by ELISA. Anti-HCV test was done by ELISA.

$\mathrm{ABO}$ and Rhesus (Rh) blood groups were determined using blood grouping antisera: anti-A, anti-B, anti-AB, and anti-D. Selection of cases for the study included the donors of MYH Blood Bank.

\section{Results and Observation}

The present study is conducted in the Department of Pathology MGM Medical College Indore and

M. Y. Hospital blood bank. This is a retrospective study that was conducted, during the period $2001-2016$. In the present study, 241571 blood donors are observed in the year 2001-16 in the M. Y. Blood Bank. The data collected from donor register record book, donors form, master record book, HIV, HBV and HCV positive beg number records. The results and observations studies are presented below:
Graph 1: Number of blood units collected during the year 2001-16.

Out of total 241571 blood donations, majority of donors are voluntary donors $68.13 \%$ as compared to replacement/ relative donors $31.86 \%$

Graph 2: Number of male and female donors during the year 2001-16.Out of total 241571 blood donations, majority of donors are male donors $96.25 \%$ as compared to female donors $3.74 \%$

Graph 3: Seropositive donors for HBV , HCV ,HIV \& SYPHILIS in 2001-16

Seroprevalence of HBV, HCV, HIV \& SYPHILIS are $1.80 \%, 0.098 \%, 0.20 \%$ and $0.26 \%$ respectively.

Graph 4: Age wise distribution of HBV , HCV ,HIV \& SYPHILIS in 2001-16

Seroprevalence is higher in the age group 26-35 years

Table 1: Seropositivity of transfusion transmitted diseases (HIV, HBV, HCV, Syphilis \& Malaria) in 200116. Among Voluntary \& replacement/relative donors. Overall seropositivity of TTI's (HIV, HBV, HCV, Syphilis \& Malaria) is higher in replacement donors $3.12 \%$ as compared to voluntary donors $2.01 \%$. Over all Seroprevalence of transfusion transmitted disease in all donations in the year $2001-16$ is $2.36 \%$.

\section{Discussion}

Voluntary or Replacement/Relative Donor - In our study, Out of total 241571 blood donations, majority of donors are voluntary donors $68.13 \%$ as compared to replacement/ relative donors $31.86 \%$

Similarly majority of donors are voluntary in another study out of 19135 blood donors, 11165 (58\%) were voluntary and $7970(42 \%)$ were replacement/relative donors by Nagarekha Kulkarni ${ }^{14}$ Associate Professor, Department of Pathology, Vijayanagara Institute of Medical Sciences, Bellary - 583104, Karnataka, India.

Male or Female Donor: In our study, .Out of total 241571 blood donations, majority of donors are male donors 96.25 $\%$ as compared to female donors $3.74 \%$. Similarly another study is comparable for majority of donors are male 96.22

Table 1: Seropositivity of transfusion transmitted diseases.

\begin{tabular}{|l|c|c|c|c|} 
S.No & $\begin{array}{c}\text { Total No of } \\
\text { Voluntary donors } \\
\text { (2001-16) }\end{array}$ & $\begin{array}{c}\text { Total No of Voluntary } \\
\text { donors found seropositive } \\
\text { for TTI (2001-16) }\end{array}$ & $\begin{array}{c}\text { Total No of } \\
\text { Replacement/relative } \\
\text { donors (2001-16) }\end{array}$ & $\begin{array}{c}\text { Total No of Replacement/ } \\
\text { relative found seropositive } \\
\text { for TTI (2001-16) }\end{array}$ \\
\hline Number & 164586 & 3319 & 76985 & 2406 \\
\hline \%age & $68.33 \%$ & $2.01 \%$ & $31.85 \%$ & $3.12 \%$ \\
\hline
\end{tabular}




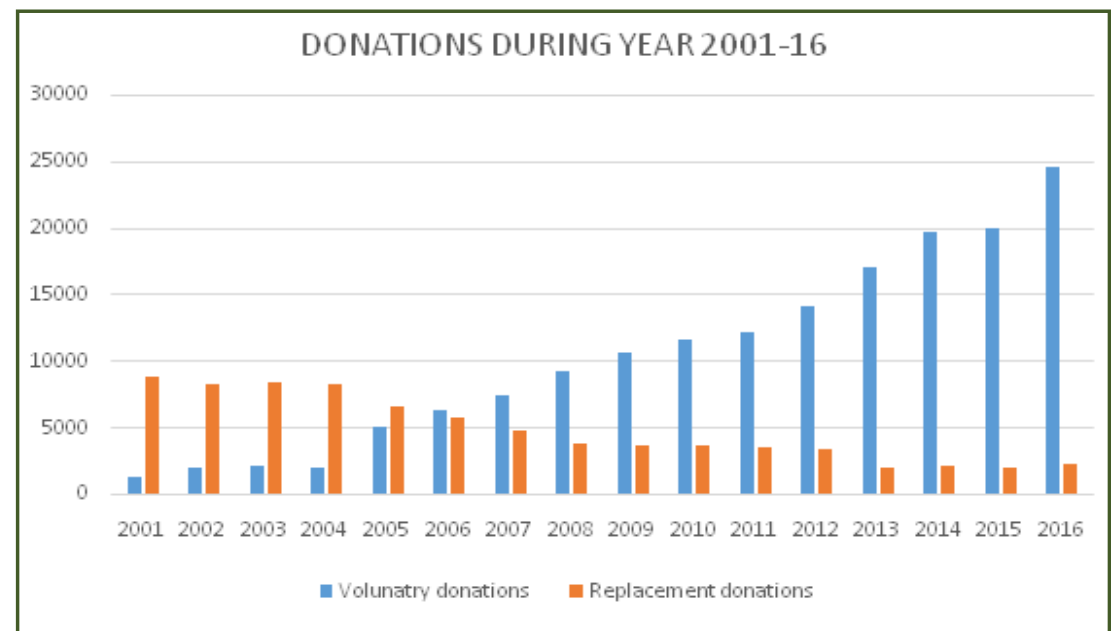

Graph 1: Number of blood units collected during the year 2001-16. Out of total 241571blood donations, majority of donors are voluntary donors $68.13 \%$ as compared to replacement/relative donors $31.86 \%$.

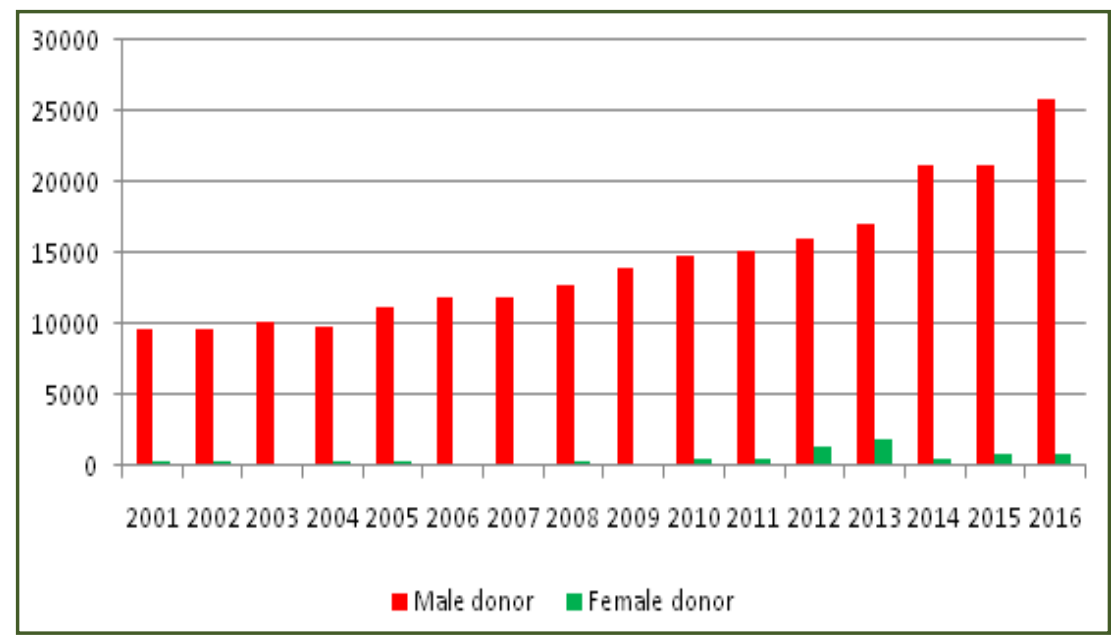

Graph 2: Number of male and female donors during the year 2001-16.0ut of total 241571 blood donations, majority of donors are male donors $96.25 \%$ as compared to female donors $3.74 \%$.

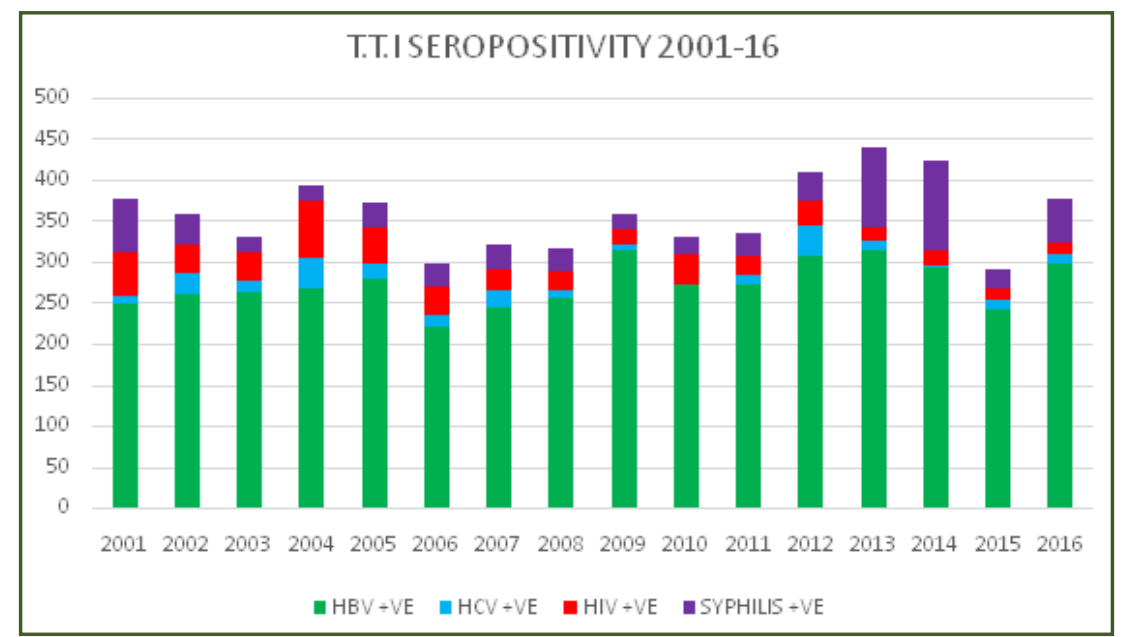

Graph 3: Seropositive donors for HBV , HCV ,HIV \& SYPHILIS in 2001-16 Seroprevalence of HBV , HCV , HIV \& SYPHILIS are $1.80 \%, 0.098 \%, 0.20 \%$ and $0.26 \%$ respectively. 


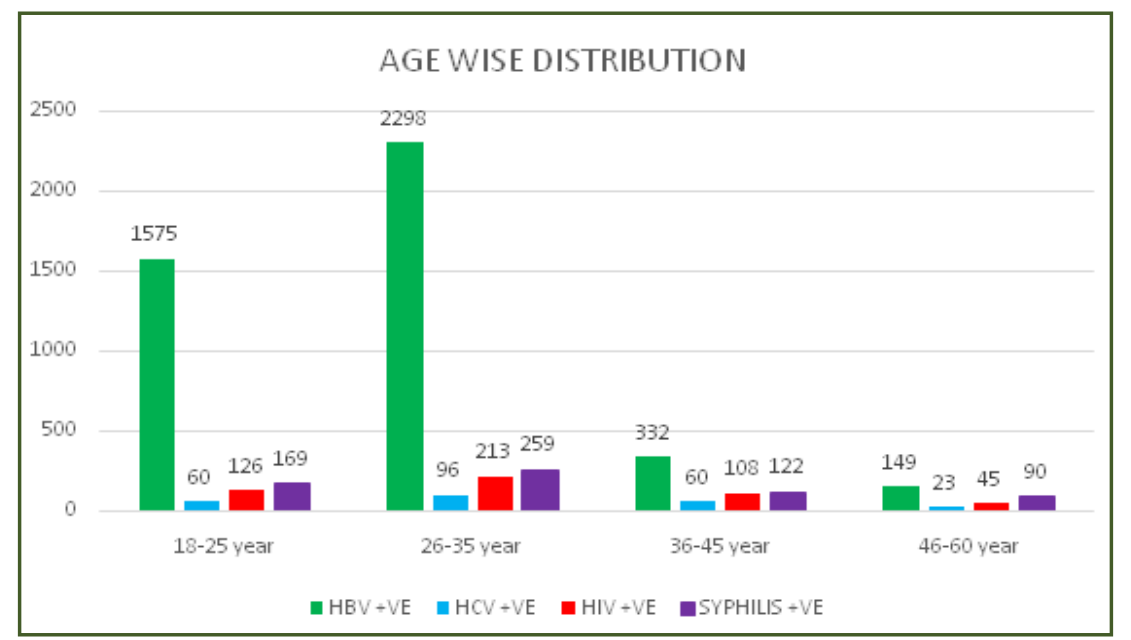

Graph 4: Age wise distribution of HBV , HCV ,HIV \& SYPHILIS in 2001-16 Seroprevalence is higher in the age group 26-35 years.

$\%$ by Arora Det all ${ }^{15}$ in Haryana. In the another study, the percentage of male patients was $73 \%$ (860/1178) as compared with $27 \%$ (318/1178) for female patients by Jain et $\mathrm{al}^{16}$ conducted in New Delhi.

Seroprevalence of HBV: In our study, the seroprevalence of HBV is $1.80 \%$ in total blood donations in the year 200116. Seroprevalence of HBV is comparable to another study with seroprevalence of HBS Ag was $1.7 \%$ by AroraD et $\mathrm{al}^{15}$ conducted in Haryana. The Seroprevalence of hepatitis B surface antigen was $0.87 \%$ noted in hospital-based population by Sood et $\mathrm{a}{ }^{17}$ conducted in Rajasthan. In another study conducted among donors of interior Sindh (Pakistan) by Mujeeb et $\mathrm{al}^{18}$, the Seroprevalence of HBV was $6.2 \%$.

Seroprevalence of $\mathbf{H C V}$; In our study, the seroprevalence of HCV is $0.098 \%$ in total blood donations in the year 2001 16. This seroprevalence is much lower than the $0.4-5.2 \%$ seroprevalence reported in an earlier study conducted in various European countries by Hahneet $\mathrm{al}^{19}$. Another study by Viet Le at $\mathrm{al}^{20}$ found HCV prevalence to be $0.17 \%$.

Seroprevalence of HIV: In our study, the Seroprevalence of HIV is $0.20 \%$ in total blood donations in the year 200116. Seroprevalence of HIV is low as compared to another study $0.3 \%$ in total donors by AroraD et $\mathrm{al}^{15}$ conducted in Haryana. In another study, the Seroprevalence of antibodies to HIV in hospital population was $0.35 \%$ by Sood et $\mathrm{al}^{17}$ conducted in Rajasthan. This is in accordance with the 2006 estimates of NACO (National AIDS Control Organization), NIHWF (National Institute of Health and Family Welfare), and NMS (National Medical Statistics) which suggest that the national adult HIV prevalence in India is $0.36 \%$. Our Seroprevalence of HIV is very low as compared with another study, the overall Seroprevalence of
HIV was $2.21 \%$ by Nagaloet $\mathrm{al}^{21}$ conducted in Koudougou. Seroprevalence of HIV is low as in another study seroprevalence of HIV was $0.91 \%$ Nagarekha Kulkarni ${ }^{14}$ in Karnataka.In our study Seroprevalence is low as compared to overall Seroprevalence of HIV (3.8\%) by Tessema et $\mathrm{al}^{22}$ conducted in University of Gondar, Ethiopia

Seroprevalence of Syphilis; Anti TP (Anti Treponema pallidum) - In our study, the Seroprevalence of Anti TP is $0.26 \%$. in total blood donations in the year 2008-15 (Graph 3).Seroprevalence of Syphilis is comparable to another study with Seroprevalence of Anti TP was $0.91 \%$ by Sultan S, Irfanm et $\mathrm{al}^{23}$ conducted in Pakistan.In another study by Elyamany $\mathrm{G}$ et $\mathrm{al}^{24}$ Seroprevalence was found to be $0.044 \%$. In a study conducted at Mangalore, India by Zulfikar A et al ${ }^{25}$ seropositivity of syphilis was found to be $0.07 \%$.

Age Wise Distribution: In our study, Seroprevalence is higher in the age group 26-35 years. . The seroprevalence of HBV was significantly higher donors in the group aged 20-29 years old than in the group 30-40 years old by Nagalo and Sanou et $\mathrm{al}^{21}$ conducted in Koudougou. The highest seroprevalence for anti-HIV was found in the age group 31-40 years by Sood et $\mathrm{al}^{19}$ conducted in Rajasthan. Seroprevalence of Anti TP (2008-15) is higher in the age group 26-35 years for anti TP $(0.09 \%)$. In a study conducted at Mangalore, India by Zulfikar A et al 25 incidence of seropositivity was found to be more in donors in the group aged 18-35 years old than in the group 36-55 years old. In a study by Tessema et $\mathrm{al}^{22}$, seropositivity of syphilis was found to be $0.9 \% \& 1.7 \%$ in age groups $17-25$ \& 26-35 yrs respectively. In another study by Elyamany $\mathrm{G}$ et $\mathrm{al}^{24}$ seropositivity was found to be highest in age group 21-30 yrs. 
Seropositivity in Voluntary/replacement Donors: Among Voluntary \& replacement/relative donors, overall seropositivity of TTI's (HIV, HBV, HCV, Syphilis \& Malaria) is higher in replacement donors $3.12 \%$ as compared to voluntary donors $2.01 \%$. Over all Seroprevalence of transfusion transmitted disease in all donations in the year 2001-16 is $2.36 \%$. (Table 1). In study by Nagarekha Kulkarni ${ }^{14}$, the seroprevalence was more in relative/replacement donors as compared to voluntary donors.

\section{Conclusion}

The present study was conducted in the Department of Pathology MGM Medical College Indore and M. Y. Hospital blood bank. This is a retrospective study that was conducted, during the period $2001-2016$. Seroprevalence of $\mathrm{HBV}, \mathrm{HCV}, \mathrm{HIV} \&$ SYPHILIS are $1.80 \%, 0.098 \%$, $0.20 \%$ and $0.26 \%$ respectively. Seroprevalence is higher in the age group 26-35 years. Overall seropositivity of TTI's (HIV, HBV, HCV, Syphilis \& Malaria) is higher in replacement donors $3.12 \%$ as compared to voluntary donors $2.01 \%$. Over all Seroprevalence of transfusion transmitted disease in all donations in the year 2001-16 is $2.36 \%$. HBV, Syphilis \& HIV are the most prevalent transfusion-transmissible diseases among blood donors in Indore. Screening and better selection of donors are necessary to improve blood safety in the regional blood transfusion centre of M. Y. Hospital. Therefore, it is concluded that voluntary blood donation should be encouraged for prevention of transfusion-transmissible diseases. The time and cost involved in screening donated blood can be reduced by an effective donor education and selection program that promotes self-exclusion by donors at risk of transfusion-transmissible infections.

\section{Acknowledgements}

We are Highly grateful to Dr C.V. Kulkarni, Prof.\& Head, Dept.of Pathologyfor providing the opportunity \& full support

\section{References}

1. Tang, J. and Kaslow, R. A. (2003). "The impact of host genetics on HIV infection and disease progression in the era of highly active antiretroviral therapy". AIDS 17 (Suppl 4): S51-S60.

2. Ronald E. Engle et al "Transfusion-associated hepatitis before the screening of blood for hepatitis risk factors". Transfusion. 2014 Nov; 54(11): 2833-2841

3. Hariri S, McKenna MT. Epidemiology of Human Immunodeficiency Virus in the United States. Clinical Microbiology Reviews. 2007;20(3):478-488.

4. World Health Organization. Global prevalence \& incidence of selected curable sexually transmitted infections: overview
\& estimates (2001). Available at : http://www.who.int/hiv/ pub/sti/en/who_hiv_aids_2014.05.pdf.

5. Kaur.G, Kaur.P : Syphilis testing in blood donors: an update. Blood Transfus 2015;13:197-204

6. Ananthnarayan.R\&Panicker C.K in Ananthnarayan. \&Panicker's Textbook of Microbiology 8th Edition Chapter 42 pg 371. University Press.

7. De Schryver A, Meheus A. Syphilis \& blood transfusion: a global perspective. Transfusion 1990;30:844-7

8. Gardella C, Marin AA, Kahn RH et al. Persons with early syphilis identified through blood or plasma donation screening in United states. J Infect Dis 2002; 185:545-9

9. Orton S. Syphilis \& blood donors: what we know, what we do not know, \& what we need to know. Transfus Med Rev 2001;15:282-91.

10. WendelNeto, Silvano. (1995). Current concepts on the transmission of bacteria and parasites by blood components. Sao Paulo Medical Journal, 113(6), 1036-1052.

11. Kaur G, Basu S, Kaur R et al. Patterns of infections blood donors in a tertiary care center: A retrospective study. Natl Med J India 2010:23;147-9

12. Bhalti FA, Ullah Z, Salamat N, et al . Anti-Hepatitis B core antigen testing, viral markers \& occult Hepatitis b infection in Pakistani blood donors: implication for transfusion practice. Transfusion 2007; 47:74-9

13. Matee MI, Magesa PM, Lyamuya EF. Seroprevalence of Human immunodeficiency virus, Hepatitis B \& C virus and syphilis infections among blood donors at Muhimbili National hospital in Dar es Salam, Tanzania. BMC Public health 2006;6:21

14. Kulkarni N. Analysis of the seroprevalence of HIV, HBsAg, $\mathrm{HCV}$ and syphilitic infections detected in the pretranfusion blood: A short report. International Journal of Blood Transfusion and Immunohematology 2012;2:1-3.

15. Arora D, Arora B, Khetarpal A. Seroprevalence of HIV, HBV, HCV and syphilis in blood donors in Southern Haryana. Indian J PatholMicrobiol 2010;53:308-9

16. Jain M, Chakravarti A, Verma V, Bhalla P. Seroprevalence of hepatitis viruses in patients infected with the human immunodeficiency virus. Indian $\mathrm{J}$ PatholMicrobiol 2009;52:17-9

17. Sood S, Malvankar S. Seroprevalence of Hepatitis B Surface Antigen, Antibodies to the Hepatitis C Virus, and Human Immunodeficiency Virus in a Hospital-Based Population in Jaipur, Rajasthan. Indian Journal of Community Medicine :2010;35(1):165-169.

18. Mujeeb SA, Pearce MS. Temporal trends in hepatitis B and $\mathrm{C}$ infection in family blood donors from interior Sindh, Pakistan. BMC Infectious Diseases. 2008;8:43.

19. Hahné SJ, Veldhuijzen IK, Wiessing L, Lim T-A, Salminen $\mathrm{M}$, Laar $\mathrm{M}$ van de. Infection with hepatitis $\mathrm{B}$ and $\mathrm{C}$ virus 
in Europe: a systematic review of prevalence and costeffectiveness of screening. BMC Infectious Diseases. 2013;13:181

20. Viet L, Lan NTN, Ty PX, et al.Prevalence of hepatitis B $\&$ hepatitis $\mathrm{C}$ virus infections in potential blood donors in rural Vietnam. The Indian Journal of Medical Research. 2012;136(1):74-81.

21. Nagalo MB, Sanou M, Bisseye C, et al. Seroprevalence of human immunodeficiency virus, hepatitis $\mathrm{B}$ and $\mathrm{C}$ viruses and syphilis among blood donors in Koudougou (Burkina Faso) in 2009. Blood Transfusion. 2011;9(4):419-424.

22. Belay Tessema et al "Seroprevalence of HIV, HBV, HCV and syphilis infections among blood donors at Gondar
University Teaching Hospital, Northwest Ethiopia: declining trends over a period of five years"BMC Infectious Diseases201010:111

23. Sultan S, Murad S Irfan m et al . Trends of venereal infections among healthy blood donors at Karachi. Arch Iran Med 2016;19(3):192-196

24. ElyamanyG,AlamroMohamed,PereiraWC,AlsuhaibaniO. Prevalence of Syphilis among Blood and Stem Cell Donors in Saudi Arabia: An Institutional Experience. Electronic Physician. 2016;8(8):2747-2751.

25. Zulfikar A, Umaru N, Shreesha K. Seroprevalence of Transfusion transmitted Infections among blood donors in Mangalore. MedicaInnov. Dec 2012, Vol 1, issue 2; 24-27

*Corresponding author:

Dr Ravi Jain, 373, Goyal Avenue, Nipania Indore 452010 INDIA

Phone: +91 09981494144

Email: ravijainpatho@gmail.com, ravij939@gmail.com 